\title{
Local HIV/AIDS NGOs and Client Satisfaction: Dimensions and Explanatory Factors through a Multilevel Regression Analysis
}

\author{
Maurice T. Agonnoude ${ }^{1 *}$ (D) François Champagne ${ }^{2}$, Nicole Leduc ${ }^{2}$ \\ ${ }^{1}$ National School of Public Health and Epidemiologic Monitoring (ENATSE), University of Parakou, Parakou, Bénin \\ ${ }^{2}$ Department of Health Policies and Evaluation (DPSE), School of Public Health (ESPUM), University of Montreal, Montréal, \\ Canada \\ Email: *amaurte@yahoo.fr, francois.champagne@umontreal.ca, nicole.leduc@umontreal.ca
}

How to cite this paper: Agonnoude, M.T., Champagne, F. and Leduc, N. (2020) Local HIV/AIDS NGOs and Client Satisfaction: Dimensions and Explanatory Factors through a Multilevel Regression Analysis. Open Journal of Epidemiology, 10, 303-322.

https://doi.org/10.4236/ojepi.2020.103025

Received: July 14, 2020

Accepted: August 24, 2020

Published: August 27, 2020

Copyright $\odot 2020$ by author(s) and Scientific Research Publishing Inc. This work is licensed under the Creative Commons Attribution International License (CC BY 4.0).

http://creativecommons.org/licenses/by/4.0/

\begin{abstract}
Background: HIV/AIDS Non-governmental organizations (NGOs) in Benin can use evaluations (including client satisfaction surveys) as tools to improve the effectiveness of their interventions. Objective: It is to identify the dimensions of NGO clients' satisfaction and their associated factors. Methods: We conducted a cross-sectional survey of 2413 clients receiving both preventive and curative services from 31 NGOs working in HIV/AIDS prevention-screening and providing care to persons living with HIV. Results: We identified four dimensions of satisfaction relevant to our setting: reception and humane attitude, accessibility of care and resources, staff availability and competence and continuity of care. Individual factors [(age positively and gender (men negatively)] statistically significantly influenced global satisfaction and three of its four dimensions but the strength of these associations was too weak. Concerning organizational factors, involvement in evaluation had a negative effect on reception and humane attitude. A local source as principal source of funding was associated with greater satisfaction with accessibility of care and resources, while foreign partners as the principal source of funding were associated with greater satisfaction in terms of both global satisfaction and its dimensions, except for continuity of care. Organizational factors explain from $12.5 \%$ to $15.6 \%$ of the variance of global satisfaction and its dimensions (except for continuity of care). Conclusion: These information on the global satisfaction and its dimensions as well as the influencing factors are important for NGOs and their partners as these can help them to plan and implement actions to improve performance.
\end{abstract}

\section{Keywords}

Local NGO, HIV/AIDS, Client Satisfaction, Individual and Organizational 
Factors, Benin

\section{Introduction}

Despite recent advances [1] the HIV/AIDS pandemic continues to have negative effects, with very harmful sociodemographic consequences in Africa [2]. To contend with this situation, countries and their technical and financial partners have become increasingly reliant on local non-governmental organizations (NGO). Despite their willingness to act, the NGOs' work is perceived as inefficient [3] [4] due to their lack of monitoring evaluation capacities [5]. As well, because NGO involvement in evaluation leads to acquisition of individual skills, strengthening of decision-making capacity [6], organizational learning [7] and results utilization, it could be a useful means for NGOs to continuously improve their programs [8] [9]. Healthcare quality comprises a set of healthcare process attributes oriented toward the best outcome possible for clients; as such, client satisfaction levels are highly relevant because they reflect consumers' perceptions of the standards achieved, their judgments of the "goodness" of care, and the extent to which providers are successful in meeting their values and expectations [10] [11] [12]. Client satisfaction surveys can be used to monitor healthcare quality for continuous improvement purposes and to help inform treatment evaluations. Moreover, client satisfaction can affect health outcomes by improving self-confidence and therapeutic compliance. It is therefore important for all health system actors to know the factors influencing that satisfaction. This paper has been written in an effort to know if local HIV/AIDS NGOs' involvement in evaluation in Benin is associated with the effectiveness of their interventions, considering client satisfaction as an indicator of effectiveness.

The general objective is to identify the dimensions of client satisfaction relating to HIV/AIDS NGOs in Benin, as well as the organizational, contextual, and individual factors associated with those dimensions.

\section{Literature Review}

\subsection{Client Satisfaction: Definition, Conceptualization}

Client satisfaction, defined as individuals' reactions to core aspects of their hospital care, is considered a critical indicator of health outcomes [13]. It is a positive attitudinal response that occurs when a given individual's cognitive evaluation of core aspects of care meets or exceeds his personal subjective standards. The literature is replete with studies of satisfaction, ranging from theoretical studies that investigate how different factors co-vary, to more detailed theoretical models based on clients' expectations, on attributes of care, and on approaches inspired by economic theories. However, there is consensus among commentators that a complete definitive conceptualization of satisfaction regarding healthcare remains to be established, and that the understanding of the process 
by which a user becomes satisfied or dissatisfied is incomplete [10] [14] [15]. According to Crow et al. [10], this difficulty of conceptualization has several explanations: views on given standards of care evolve; satisfaction expresses users' experience, knowledge and expectations regarding care, rather than the actual quality of the service and care provided; it is hard to separate feelings of satisfaction or dissatisfaction with the service delivery or process of care from those related to the outcome of care (health status) because of the complex reciprocal nature of the relationship between health outcomes and satisfaction with care; and, finally, theories of cognitive dissonance predict that people will not admit to dissatisfaction with services they have chosen to use. Other complexities in measurement arise when people express different degrees of satisfaction with their personal care and with the healthcare system in general. For these reasons, the aim of this paper is not to elaborate a conceptual framework, but rather to identify, in one particular setting, the relevant dimensions of satisfaction and different individual (age, gender, length of frequentation) or organizational (level of involvement in evaluations, principal source of funding, intervention domain, geographic area, experience of NGO, procedure for taking clients' opinions in account, staff's number) factors associated with satisfaction and/or its dimensions.

\subsection{Dimensions of Satisfaction}

Sitzia et al. [15], inspired by Donabedian's framework for health services evaluation, considered patient satisfaction to consist of measuring the process of care in order to isolate problems areas and generate solutions. This process encompasses eight aspects, which can be seen as the dimensions of satisfaction: interpersonal demeanour; technical quality of care; accessibility and convenience; material and financial resources; efficacy or outcomes of care; continuity of care; physical environment; and availability. Many satisfaction studies conducted in very specific contexts reveal the importance of one or another dimension of satisfaction. The interpersonal and relational skills of healthcare providers, the clarity of diagnostic and therapeutic communications and of specific information received from providers, the role played by providers in terms of helping clients maintain health status (e.g., preventive healthcare counselling), length of inpatient stays, and the convenience of location and hours available for outpatients are some of the dimensions of satisfaction identified by Ashley and Strasser [16]. Mishra and Mishra [17] took into account these dimensions while adding courtesy of staff at admission counter, behavior and cooperation of nurses, cleanliness of toilets, quality of food, explanation about rules and regulation, behavior of orderlies and sanitary attendant and room preparedness. Thornton et al. [18] identified satisfaction with Physician, availability/convenience, and orderly/time as major dimensions. Fan et al. [19] emphasized the important role of continuity of care in satisfaction, while Larson et al. [20] reaffirmed the importance of healthcare providers' ability to communicate information as fundamental to both quality of care and patients' quality of life. Ahenkan and Aduo-Adjei 
[21] in Ghana added effective communication, empathy, culture, tangibles, and priority as important dimensions of patient satisfaction. In South Africa, in a study on health system responsiveness, Peltzer [22] identified four major priority areas for action, including healthcare access and communication. In North East India Rajkumari and Nula [23] found that physician and nursing care, comfort and cleanliness of the wards and quality of food service were the dimensions of concerns for patient's satisfaction in public facilities. In the case of post-test counselling for HIV-infected women in Vietnam, Nguyen Thi et al. [24] discovered that it was not only medical care but also social and emotional support offered by healthcare staff which were most important for women's satisfaction. Tehrani et al. [25] found that wait time and time spent by providers with patients were most important, while at the end of their literature review, Crow et al. [10] concluded that the patient-practitioner relationship, the ability to choose the service provider, and the healthcare payment methods were the most important dimensions. Thus, clients' expectations of healthcare systems are characterized by a multitude of dimensions in a variety of contexts, and it is important in any given context to clearly identify the relevant dimensions in order to be more effective in satisfying clients. However, all of the above components of satisfaction can be seen as representing management agendas for healthcare rather than patients' concerns [15]. Also, in our context of fighting an HIV/ADS epidemic in a developing country, dimensions such as care access and professional empathy are probably also important. Given that several studies conducted in different contexts uncovered different relevant dimensions, there is no single standard classification of satisfaction dimensions that is fully appropriate; therefore, it was important in this study to start with a questionnaire combining the most frequently used dimensions in the literature to find out which were most relevant to our context.

\subsection{Factors Influencing Client Satisfaction}

There are multiple factors influencing client satisfaction, which depend not only on individuals (providers and patients), but also on the organizational, political or social contexts in which the intervention is operating. From an organizational standpoint, Coovadia [26] in South Africa found that client satisfaction was best explained by the kind of hospital structure (private or health maintenance organization). In England, Aiken et al. [27] found that patient's satisfaction was strongly associated to poor professional nurse $(\mathrm{RN})$ staffing and poor hospital work environments. Grytten et al. [28], in a study on primary healthcare in Norway, saw a positive and relatively strong association between general practitioners' level of service production and patient satisfaction. With regard to care for persons living with HIV, Fleishmann et al. [29] found, in studying the implementation of case management services, that the kind of provider (private clinic or community-based organization) explained client satisfaction, with patients in private clinics being more disadvantaged. In primary healthcare facilities in the Free State (South Africa), human resource shortages (leading to long 
wait times) were one of the most important predictors of discontent among antiretroviral treatment (ART) patients [30]. With regard to individual factors, age [31] [32] [33] [34], gender [34] [35], marital status [35], level of education [18] [32] [36], previous admission [36], social class [31], duration at the clinic [18] and health condition [18] [31] [32] [33] [35] are the sociodemographic variables seen in the literature which appear to predict client satisfaction. However, these sociodemographic variables are unreliable predictors, as there is no consensus on their effect on client satisfaction [10] [14] [15]. Given that some factors are linked to organizations and others to individuals, this two-level information structure requires an understanding of client satisfaction at multiple levels for at least two reasons, according to Hekkert et al. [32]. First, information about the relative importance of each level can be essential for planning effective quality improvements; when it is known at which level satisfaction is determined, more specific policy improvements can focus on that particular level. Second, the amount of explained variance at each level is important for determining the case-mix adjusters to be used in satisfaction surveys. The goal of our study, therefore, is to identify the dimensions and associated factors of client satisfaction in the context of HIV/AIDS NGOs in Benin. Our intention in this paper is to test the effect of a set of variables found in the literature on client satisfaction and its dimensions. At the individual level, we examine the effects of age, gender and length of affiliation (e.g. are older women who have been attending a given NGO for a long time more satisfied than young men who have begun attending the same NGO more recently?). At the organizational level, we explore the effect of variables such as the intervention setting, the type of funding, the number of staff, the NGO's involvement in evaluation, the procedure for taking into account clients' perspectives, the type of NGO and its experience, and the patients' health status. For instance, do the more experienced NGOs in urban areas that have foreign funding and a high number of staff, provide care for persons living with HIV, and are highly involved in evaluation, carrying out regular satisfaction surveys, have the more satisfied clients?

\section{Methods}

This was a cross-sectional study of clients of NGOs involved in prevention and screening and provision of care to persons living with HIV.

\subsection{Sampling}

The inclusion criteria for the NGOs were: 1) to have been recognized and was being registered for a minimum of three years by the national authorities; and 2) to have worked either in HIV/AIDS counselling and screening, or in medical or psychosocial care for people living with HIV/AIDS, for at least three years. The sample size necessary to detect, in a hypothesis test, a statistically significant difference (the effective NGO proportion within NGO involved in evaluation is higher than that of NGO not involved in evaluation), with a power $i=10 \%$ ( $\beta=$ 
90\%) and a cut-off threshold $\alpha=0.05$, is given by Schwartz formula: $n=\varepsilon^{2} p(1-$ $p) / I^{2}=96.4 \approx 100$ (where $p=0.5$ ). Convenient sampling method was used to select NOGOs. A total of 161 NGOs assumed by the Ministry of Health to be working actively in this field were contacted and met the inclusion criteria; of these, only 62 were registered (38.51\% of the original population). From this group, 34 NGOs accepted to participate in the study, for a recruitment success rate of $54.84 \%$. A comparison of the participating NGOs group $(n=34)$ with the group of those that declined $(n=28)$ and the rest of the original group $(n=99)$ showed no statistically significant difference in terms of department distribution $(p=0.602)$, geographical area $(p=0.667)$ or field of intervention $(p=0.505)$. For each NGO, the sample size necessary to detect, in a hypothesis test, a statistically significant difference, with a power $i=10 \%(\beta=90 \%)$ and a cut-off threshold $\alpha$ $=0.05$, is given by Schwartz formula: $n=\varepsilon^{2} p(1-p) / \stackrel{I}{I}^{2} 96.4 \approx 100$ (where $p=$ $0.5)$. Accidental sampling method was used to select NGOs clients. Adult clients, men or women, were informed over the course of a week through posters and periodic information sessions in the waiting rooms of NGOs regarding the study's objectives, the voluntary nature of the participation, the desired collaboration, and the survey sites. As volunteers consented, they were interviewed at the suitable place of them one after another using a satisfaction questionnaire until the desired number was attained in each NGO. This survey was not possible in three NGOs because of scheduling conflicts. In the 31 remaining NGOs, the number of enrolled clients ranged from 19 to 102. In all, 2413 clients were surveyed, an average of 78 per NGO.

\subsection{Definition of Variables}

- The main dependent variable is the score of clients' global satisfaction with the NGO: a perceptual index measured using a 5-point Likert scale (very satisfying, satisfying, medium satisfying, low satisfying, unsatisfactory) in a satisfaction survey. The other dependent variables are the dimensions of satisfaction identified in the data analysis for all patients.

- The independent variables are, on one hand, patients' sociodemographic variables (age, gender, and length of affiliation, i.e., how long the client had been obtaining services in this facility) and, on the other hand, the characteristics of the NGO: type of NGO (prevention and screening or care for persons living with HIV), the principal source of funding (local, foreign partners or foreign countries), geographic location (rural or urban), staff numbers (in full-time equivalents), experience (in years), the procedure used to take clients' perspectives into account, and the NGO's level of involvement in evaluation (continuous variable with ratio scale obtained from a questionnaire survey of the NGOs' leaders).

\subsection{Data Collection Methods}

The data was collected during individual interviews with the clients either in 
their house, in their work area or in a site closes to the NGO's office. These interviews were conducted between December 26, 2010, and February 28, 2011, by interviewers hired and trained especially for that purpose, under the supervision of the principal investigator. Because the questionnaire was in French, interviewers were chosen in each survey region based on their knowledge of both French and the local language, and were trained to ensure they were able to translate questions correctly into their local language. As our sample included both persons receiving curative care and those receiving preventive services, the questionnaire we used was adapted from two tested and validated questionnaires: that of Haddad et al. [37] on patients' perceptions of basic healthcare quality in developing countries, and that of Wilson et al. [38] for measuring client satisfaction with intermediate care. The resulting 17-item questionnaire was divided into seven parts. The first part, with five items, collected clients' general impressions and their assessment of the sympathy, respect, open-mindedness, and time and attention shown to them by the NGO's staff. The second part included four items to obtain their assessment of the psychological and physical care (exams, care, information, follow-up) they received from the staff. The two items of the third part were related to the NGOs' human and material resources. The fourth part, with three items, considered care continuity over the course of successive appointments at the facility or in cases of referral to other facilities. The fifth part consisted of two items focused on the financial or geographic accessibility of the facility. The sixth and seventh parts, with one item each, were related to the staff's availability to respond to all clients' requests, and to psychological care, respectively.

For the organizational data, two methods of data collection were used:

- Document consultation: partnership contracts between the funding entity and the NGO (self-evaluation requirement from partner), organizational charts or job descriptions (description of role or function in evaluation); periodic reports with financial information (specific resources for evaluation in the budget);

- Questionnaires completed by NGO agents [executive managers (73.5\%), programs manager $(14.7 \%)$ or other managers $(11.8 \%)]$ in charge of monitoring and evaluating programs, with closed questions administered by the principal investigator during an interview.

\subsection{Data Quality}

- This data collection tool was pre-tested with 20 clients in NGOs with characteristics similar to those of our sample. Based on this pre-test, we reformulated or divided some questions to make them more understandable for respondents.

\subsection{Data Analysis}

- The first part of the analysis was a principal components analysis (PCA) of the 17 items of the satisfaction questionnaire, to identify a reduced number 
of dimensions to incorporate as dependent variables into the subsequent analysis. According to Hair et al. (1998), quoted by Yergeau and Poirier (2011) [39], PCA is a multivariate interdependence technique which is used, among other things, to compress the information contained in a large number of variables into a more restrained set of new composite dimensions while assuring minimal information loss. We therefore used the exploratory approach to reduce the 17 items to a few dimensions of satisfaction. This analysis was performed using SPSS version 17.0. We used Castell's elbow (the inflection point on the graph constituted by the eigenvalues) as the criterion to define the number of dimensions to retain. A Varimax rotation was done. We carried out internal consistency analysis of the identified new dimensions with Cronbach's alpha estimates.

- To assess what portion of the explained variance of global satisfaction (and of its dimensions) was linked to individual factors (level 1) or to organizational factors (level 2), we performed a multilevel linear regression analysis. We estimated the intra-class correlations (ICC) corresponding to a percentage of the total explained variance linked to NGO characteristics. We first calculated ICCs using a null model (Model 0) with random intercept and models with only individual variables (Model 1) for each dependent variable. Then we used stepwise modelling, introducing the independent organizational variables one by one and removing non-significant variables as the procedure progressed. The final models retained (Model 2) were those with the greatest number of statistically significant independent variables, since our objective was to identify predictors of client satisfaction and its dimensions. Finally, adjusted ICCs were estimated for these final models. The cut-off threshold for conclusions was $\alpha \leq 0.05$.

\section{Results}

\subsection{Sample Characteristics}

\subsubsection{Baseline Characteristics of NGOs and Clients Samples}

This study was about 2413 clients from 31 NGOs. The clients' mean age was 27.32 years ( \pm 8.81 years), and $35.3 \%$ of them were men. Table 1 and Table 2 present the distributions of clients and of NGOs according to the independent variables.

\subsubsection{Dimensions of Satisfaction}

Our procedure excluded observations with missing data, leaving 877 observations. The results showed that the assumptions for this procedure were met, as there was minimal correlation between items. The KMO index was excellent, at 0.88 [39], and Bartlett's test of sphericity was significant $(p<0.001)$; thus, the null hypothesis that there was an identity matrix was rejected, which meant all the items were independent of each other. We retained four dimensions. The analysis of the components matrix after Varimax rotation with Kaiser normalization is presented in Table 3 , in which we see the weight of each item making 
Table 1. Characteristics of the NGO sample.

\begin{tabular}{cccc}
\hline & $\begin{array}{c}\text { Level of involvement in } \\
\text { evaluation }\end{array}$ & Staff numbers & \\
Mean & 5.61 & 19.48 & Experience $^{3}$ \\
Standard deviation & 2.20 & 17.33 & 12.39 \\
Mode & 5 & 9 & 4.23 \\
Median & 5 & 15 & 4.21 \\
\hline
\end{tabular}

Table 2. Characteristics of NGOs and client samples.

\begin{tabular}{|c|c|c|}
\hline & NGOs $(n=31)$ & Clients $(n=2413)$ \\
\hline \multicolumn{3}{|c|}{ Geographic area } \\
\hline Rural & $18(58.1 \%)$ & $1357(56.2 \%)$ \\
\hline Urban or semi-urban & $13(41.9 \%)$ & $1056(43.8 \%)$ \\
\hline \multicolumn{3}{|c|}{ Intervention domain } \\
\hline HIV/AIDS care & $3(9.7 \%)$ & $265(11 \%)$ \\
\hline Prevention screening & $28(91.3 \%)$ & $2148(89 \%)$ \\
\hline \multicolumn{3}{|c|}{ Principal source of funding } \\
\hline Local funding & $15(48.4 \%)$ & $986(40.9 \%)$ \\
\hline Foreign partners & $10(32.3 \%)$ & $840(34.8 \%)$ \\
\hline Foreign country & $6(19.3 \%)$ & $587(24.3 \%)$ \\
\hline \multicolumn{3}{|c|}{ Procedure for taking into account clients' perspectives } \\
\hline None & $11(35.5 \%)$ & $693(28.7 \%)$ \\
\hline Suggestion box & $7(22.6 \%)$ & $539(22.3 \%)$ \\
\hline Complaints registration and processing & $4(12.9 \%)$ & $349(14.5 \%)$ \\
\hline Regular satisfaction surveys & $9(29.0 \%)$ & $832(34.5 \%)$ \\
\hline
\end{tabular}

up the four dimensions, which are: staff availability and competence and sufficiency of resources (dimension 1); reception and humane attitude (dimension 2); accessibility of care and resources (dimension 3); and finally continuity of care (dimension 4). The eigenvalue of each item for each dimension is above 0.5 . These four dimensions are seen more clearly after Varimax rotation and correspond to ${ }^{1}$ Involvement is defined by a combination of six categorical variables on an ordinal scale (values from 0 to 2): 1) existence in the budget of specific financial resources for evaluation (no resources, insufficient resources sufficient resources); 2) existence and quality of human resources available for evaluation (no human resources, person or team with only field experience, team with graduate training); 3) annual frequency of learning opportunities and discussion of evaluation results in the NGO (inexistent, 1 to 3,4 and more); 4) annual frequency of new monthly data being incorporated into evaluation data in the NGO (4 or less, 5 to 8,9 to 12 ); 5) existence of an evaluation structure in the NGO's organization chart and its association with the conception of new programs (nonexistent; existing but without contribution; existing and operational); and 6) level of NGO staff s participation in evaluations (low, medium, high). It's a continuous variable with ratio scale obtained from a questionnaire survey of the NGOs' leaders.

${ }^{2} \mathrm{NGO}$ standing, contractual or voluntary staff numbers (in full-time equivalents).

${ }^{3}$ Experience of NGO: time passed from the NGO's foundation (in years). 
Table 3. Principal components analysis: extraction of four factors $(n=877)$ with components matrix after Varimax rotation with Kaiser normalization.

\begin{tabular}{|c|c|c|c|c|}
\hline & Factor 1 & Factor 2 & Factor 3 & Factor 4 \\
\hline Client follow-up by NGO staff & 0.591 & 0.379 & 0.412 & 0.078 \\
\hline Client exams or counselling by the staff & 0.670 & 0.284 & 0.191 & 0.133 \\
\hline Relevancy of care and information provided to clients & 0.733 & 0.235 & 0.072 & 0.151 \\
\hline Availability of the staff & 0.782 & 0.069 & -0.119 & 0.064 \\
\hline Attention to psychological concerns & 0.484 & 0.055 & 0.184 & 0.342 \\
\hline Satisfying responses to clients' needs by the staff & 0.127 & 0.639 & -0.017 & 0.048 \\
\hline Time and attention given to clients & 0.526 & 0.508 & 0.257 & -0.142 \\
\hline Open-mindedness of the staff toward the clients & 0.146 & 0.809 & 0.146 & 0.007 \\
\hline Respect of the staff toward the clients & 0.185 & 0.809 & 0.049 & -0.026 \\
\hline Compassion of the staff toward the clients & 0.191 & 0.755 & -0.038 & 0.159 \\
\hline Financial accessibility & 0.155 & 0.161 & 0.818 & 0.078 \\
\hline Geographic accessibility & 0.166 & -0.103 & 0.756 & 0.013 \\
\hline Appropriateness of the staff of the NGO & 0.650 & 0.236 & 0.412 & 0.079 \\
\hline Appropriateness of the facilities of the NGO & 0.508 & 0.059 & 0.382 & 0.172 \\
\hline Continuity: same nurse for subsequent visits & 0.190 & 0,053 & 0.101 & 0.871 \\
\hline Continuity: later visits taking into account earlier ones & 0.129 & 0.042 & 0.005 & 0.899 \\
\hline Continuity during referrals to others centres & 0.563 & 0.204 & 0.378 & 0.110 \\
\hline Eigenvalue of the factor & 6,018 & 1,944 & 1,503 & 1,008 \\
\hline Percentage of explained variance after rotation & $24.028 \%$ & $19.349 \%$ & $12.296 \%$ & \\
\hline Total explained variance for the four factors & $61.604 \%$ & & & \\
\hline
\end{tabular}

$61.604 \%$ of the explained total variance. However, four items are correlated with the items of dimension 1, to which they do not belong conceptually. These are: continuity of care when patients are referred to another centre, which is conceptually close to dimension 4 ; the time and attention given to clients, which is conceptually close to dimension 2; and finally, the two resource items (human and material resources), which are conceptually close to dimension 3, accessibility of care and resources. Before proceeding to the next step, we set up a scale that took into account these modifications. All four dimensions were statistically significantly correlated to global satisfaction $(p<0.001)(\rho=0.825$ for dimension 3; $\rho=0.671$ for dimension $4, \rho=0.751$ for dimension 2 , and $\rho=0.842$ for dimension 1), showing that these dimensions effectively measured client satisfaction for the NGOs. However, inter-dimension correlations were relatively low (from 0.192 for dimensions 2 and 4 to 0.635 for dimensions 1 and 2), showing that, while they measure the same thing, these dimensions underline different aspects of this satisfaction. We then assessed the internal consistency of each of the four dimensions by computing Cronbach's alpha coefficients. The results are shown in Table 4. All the dimensions have high enough internal consistency, 
Table 4. Characteristics of the four new dimensions.

\begin{tabular}{ccccc}
\hline \multirow{2}{*}{ Characteristics } & \multicolumn{4}{c}{ Dimensions } \\
\cline { 2 - 5 } & $\begin{array}{c}\text { Staff availability } \\
\text { and competence }\end{array}$ & $\begin{array}{c}\text { Reception and } \\
\text { humane attitude }\end{array}$ & $\begin{array}{c}\text { Accessibility of } \\
\text { care and resources }\end{array}$ & $\begin{array}{c}\text { Continuity of } \\
\text { care }\end{array}$ \\
\hline Number of items & 5 & 5 & 4 & 3 \\
Average mean score & 19.30 & 20.12 & 13.59 & 10.37 \\
Average value of score & 3.93 & 4.02 & 3.49 & 3.44 \\
Variance & 7.68 & 8.059 & 6.685 & 5.225 \\
Cronbach's $\alpha$ & 0.725 & 0.808 & 0.504 & 0.645 \\
Average inter-item correlation & 0.362 & 0.465 & 0.207 & 0.365 \\
Lowest inter-item correlation & 0.262 & 0.406 & 0.038 & 0.195 \\
Highest inter-item correlation & 0.544 & 0.573 & 0.333 & 0.669 \\
\hline
\end{tabular}

with Cronbach's alphas ranging from 0.501 to 0.808 . The low internal consistency obtained for the last two dimensions may be related to the fact that these dimensions had only a few items in the questionnaire. Table 4 also presents descriptive statistics for the four dimensions.

\subsection{Bivariate Analysis}

Male gender, no procedure or the simple procedure used to take into account clients' perspectives, and the NGOs' level of involvement in evaluation were all statistically significantly negatively linked to the four identified dimensions as well as to global satisfaction. NGOs' experience and foreign countries as principal source of funding were statistically significantly negatively linked to global satisfaction and some of the four dimensions (experience did not influence accessibility of care and resources and was positively linked to satisfaction for continuity, and principal source of funding was not linked to satisfaction for continuity of care). Client age and type of NGO influenced all the dimensions in a statistically significant manner but showed no effect on global satisfaction, while urban or suburban NGO influenced negatively global satisfaction and two of the dimensions (satisfaction for accessibility of care and resources and for continuity of care). Length of affiliation with the NGO influenced three dimensions in different manner (negative influence toward satisfaction for reception and humane attitude, accessibility of care and resources, and positive influence toward continuity of care), while number of staff influenced negatively satisfaction for staff availability and competence and positively satisfaction for accessibility of care and resources, even though these two variables had no influence on global satisfaction. Bivariate analyses between the independent variables showed that overall, they influenced each other. But, for the pairs of continuous independent variables, we noted that the correlations fluctuated between -0.284 and 0.437 , which are relatively low, suggesting a low likelihood of collinearity.

\subsection{Multilevel Linear Regression Analysis}

Table 5 presents the results of the analysis. The first observation is that all ICCs 
Table 5. (a) Models of linear multilevel regression with fixed and random effects for global satisfaction and its dimensions; (b) Models of linear multilevel regression with fixed and random effects for global satisfaction and its dimensions (cont.).

(a)

Dependent variables

\begin{tabular}{|c|c|c|c|c|c|c|c|c|c|}
\hline \multirow{2}{*}{$\begin{array}{c}\text { Characteristics } \\
\text { Fixed effects }\end{array}$} & \multicolumn{3}{|c|}{$\begin{array}{l}\text { Staff availability and competence } \\
\qquad n=2413\end{array}$} & \multicolumn{3}{|c|}{$\begin{array}{l}\text { Reception and humane attitude } \\
\qquad N=2404\end{array}$} & \multicolumn{3}{|c|}{$\begin{array}{l}\text { Accessibility of care and resources } \\
\qquad N=2281\end{array}$} \\
\hline & Model 0 & Model 1 & Model 2 & Model 0 & Model 1 & Model 2 & Model 0 & Model 1 & Model 2 \\
\hline Intercept & $3.95^{\star *}$ & $3.897^{* *}$ & $3.78^{\star *}$ & $4.040^{* *}$ & $3.970^{* *}$ & $3.870^{* *}$ & $3.560^{* *}$ & $3.450^{* *}$ & $3.350^{* *}$ \\
\hline Age & - & $0.003^{*}$ & $0.003^{*}$ & - & $0.004^{* *}$ & $0.004^{* *}$ & - & $0.005^{\star *}$ & $0.005^{\star *}$ \\
\hline Gender male & - & $-0.07^{\star *}$ & $-0.07^{\star *}$ & - & $-0.100^{* *}$ & $-0.100^{* *}$ & - & $-0.084^{\star *}$ & $-0.085^{\star *}$ \\
\hline Level of involvement in evaluation & - & - & - & - & - & $-0.053^{*}$ & - & - & 0.077 \\
\hline Intervention area: urban & - & - & -0.21 & - & - & 0.114 & - & - & $-0.386^{*}$ \\
\hline Principal source & - & - & 0.344 & - & - & $0.349^{*}$ & - & - & $0.687^{\star *}$ \\
\hline of funding Foreign partners & - & - & $0.606^{* *}$ & - & - & $0.493^{* *}$ & - & - & $0.669^{* *}$ \\
\hline \multirow{2}{*}{$\begin{array}{cc} & \text { Regular } \\
\text { Procedure for } & \text { satisfaction surveys } \\
\text { taking into } & \text { Complaint } \\
\text { account clients' } & \text { recording and } \\
\text { perspectives } & \text { processing }\end{array}$} & - & - & $0.294^{*}$ & - & - & $0.295^{\star}$ & - & - & - \\
\hline & - & - & 0.051 & - & - & 0.05 & - & - & - \\
\hline Suggestion box & - & - & 0.350 & - & - & 0.125 & - & - & - \\
\hline NGO experience & - & - & -0.027 & - & - & - & - & - & $-0.055^{\star}$ \\
\hline \multirow[t]{2}{*}{ Random effects } & ICC & $\begin{array}{c}\text { ICC } \\
\text { adjusted } 1\end{array}$ & $\begin{array}{c}\text { ICC } \\
\text { adjusted } 2\end{array}$ & ICC & $\begin{array}{c}\text { ICC } \\
\text { adjusted } 1\end{array}$ & $\begin{array}{c}\text { ICC } \\
\text { adjusted } 2\end{array}$ & ICC & $\begin{array}{c}\text { ICC } \\
\text { adjusted } 1\end{array}$ & $\begin{array}{c}\text { ICC } \\
\text { adjusted } 2\end{array}$ \\
\hline & $0.402^{* *}$ & $0.395^{\star *}$ & $0.270^{* *}$ & $0.388^{* *}$ & $0.378^{* *}$ & $0.250^{* *}$ & $0.600^{* *}$ & $0.600^{* *}$ & $0.469^{* *}$ \\
\hline$-2 \log$ restricted likelihood & 3099.046 & 3085.498 & 3068.299 & 2923.619 & 2896.121 & 2878.229 & 3054.844 & 3032.059 & 3016.148 \\
\hline Significance test M2/M1 & & & $p<0.025$ & & & $p<0.025$ & & & $p<0.001$ \\
\hline
\end{tabular}

${ }^{* *} p<0.001 ;{ }^{*} p<0.05$.

(b)

\begin{tabular}{|c|c|c|c|c|c|c|}
\hline \multirow[b]{2}{*}{ Independent variables } & \multicolumn{6}{|c|}{ Dependent variables } \\
\hline & \multicolumn{3}{|c|}{$\begin{array}{l}\text { Continuity of care } \\
\qquad n=1696\end{array}$} & \multicolumn{3}{|c|}{$\begin{array}{c}\text { Global satisfaction } \\
\qquad n=2398\end{array}$} \\
\hline Fixed effects & Model 0 & Model 1 & Model 2 & Model 0 & Model 1 & Model 2 \\
\hline Intercept & $3.40^{* *}$ & $3.32^{* *}$ & $3.13^{* *}$ & $3.81^{\star *}$ & $3.76^{\star *}$ & $3.75^{\star *}$ \\
\hline Age & - & 0.003 & 0.003 & - & $0.002^{*}$ & $0.002^{*}$ \\
\hline Gender Male & - & -0.007 & -0.007 & - & $-0.067^{\star *}$ & $-0.068^{* *}$ \\
\hline Level of involvement in evaluation & & & -0.074 & & - & - \\
\hline Intervention area: urban & - & - & -0.256 & - & - & $-0.377^{\star *}$ \\
\hline Principal source of & - & - & 0.310 & - & - & $0.488^{*}$ \\
\hline Foreign partners & - & - & 0.273 & - & - & $0.620^{*}$ \\
\hline Regular satisfaction surveys & - & - & - & - & - & 0.250 \\
\hline \multirow[t]{2}{*}{$\begin{array}{l}\text { Procedure for taking } \\
\text { into account clients' Complaint registration and } \\
\text { perspectives }\end{array}$} & - & - & - & - & - & 0.305 \\
\hline & & - & - & - & - & 0.294 \\
\hline
\end{tabular}




\begin{tabular}{|c|c|c|c|c|c|c|}
\hline NGO experience & - & - & 0.022 & - & - & $-0.033^{\star}$ \\
\hline \multirow[b]{2}{*}{ Random effects } & ICC & ICC adjusted 1 & ICC adjusted 2 & ICC & ICC adjusted 1 & ICC adjusted 2 \\
\hline & $0.511^{* *}$ & $0.509^{* *}$ & $0.447^{* *}$ & $0.547^{\star *}$ & $0.544^{\star *}$ & $0.388^{* *}$ \\
\hline$-2 \log$ restricted likelihood & 2724.235 & 2719.660 & 2714.667 & 1875.731 & 1856.862 & 1837.949 \\
\hline Significance test M2/M1 & & $p>0.05$ (ns) & $p>0.05$ (ns) & & & $p<0.01$ \\
\hline
\end{tabular}

${ }^{* *} p<0.001 ;{ }^{*} p<0.05$.

were statistically significant at the 0.01 threshold and fluctuated between 0.39 and 0.60 for the null models, between 0.378 and 0.600 for M1 models, and between 0.270 and 0.469 for the complete models. This result shows the relevance of using a multilevel model rather than multiple linear regression to analyze these data, as a substantial portion of the explained variance was at the organizational level. The second observation is that M2 models adjusted the data well for global satisfaction and its dimensions in chi-squared tests [40] [41], except for continuity of care (which none of the independent variables was able to predict). The third observation is that individual factors (age and gender) statistically significantly influenced global satisfaction and three of its four dimensions (satisfaction increased slightly with age, with the exception of continuity of care, and women were slightly more satisfied than men). Concerning organizational factors, we noted that involvement in evaluation had a negative effect on reception and humane attitude, as did intervention area and NGO experience on global satisfaction and accessibility of care and resources. The principal source of funding had an effect on global satisfaction and on some of its dimensions; a local source was associated with greater satisfaction with accessibility of care and resources, while foreign partners as the principal source of funding was associated with greater satisfaction in terms of both global satisfaction and its dimensions, except for continuity of care. Using regular satisfaction surveys as a procedure to take into account clients' perspectives had a positive effect on satisfaction for staff availability and competence and on satisfaction for reception and humane attitude. The other independent variables had no effect on global satisfaction nor on any of its dimensions. Table 6 summarizes all the independent variables tested in the study.

\section{Discussion}

The four relevant dimensions of satisfaction in our context are reception and humane attitude, staff availability and competence, accessibility of care and resources, and continuity of care. Haddad et al. [37], in a study to test and validate a questionnaire for evaluation of primary care quality by clients in Guinea, went from a 20 -item questionnaire to a scale with three dimensions: service offer, staff and facilities. Wilson et al. [38], in developing and testing a questionnaire to measure patients' satisfaction with intermediate care in Great Britain, identified six dimensions: global satisfaction, affective response, cognitive response, timing 
Table 6. Independent variables and their relation to global satisfaction and its dimensions.

\begin{tabular}{|c|c|c|c|c|c|c|c|}
\hline & & & \multicolumn{5}{|c|}{ Dependent variables } \\
\hline \multicolumn{3}{|c|}{ Independent variables } & $\begin{array}{l}\text { Staff availability } \\
\text { and competence }\end{array}$ & $\begin{array}{l}\text { Reception and } \\
\text { humane attitude }\end{array}$ & $\begin{array}{l}\text { Accessibility of } \\
\text { care and Resources }\end{array}$ & $\begin{array}{l}\text { Continuity of } \\
\text { care }\end{array}$ & $\begin{array}{c}\text { Global } \\
\text { satisfaction }\end{array}$ \\
\hline \multirow{3}{*}{ 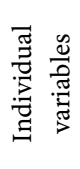 } & & Age & + & + & + & ns & + \\
\hline & & Gender & - & - & - & ns & - \\
\hline & Lengt & th of frequentation & Ns & ns & $\mathrm{ns}$ & ns & ns \\
\hline \multirow{10}{*}{ 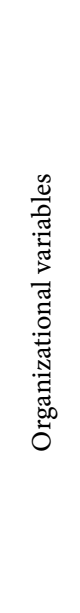 } & Involve & rement in evaluation & Ns & - & ns & ns & ns \\
\hline & Intervention & n domain: care for PLHIV & Ns & ns & ns & ns & ns \\
\hline & & Regular satisfaction surveys & + & + & ns & ns & ns \\
\hline & $\begin{array}{l}\text { Procedure for } \\
\text { clients' opinion }\end{array}$ & $\begin{array}{c}\text { Complaints registration and } \\
\text { processing }\end{array}$ & Ns & ns & ns & ns & ns \\
\hline & & Suggestion box & Ns & ns & ns & ns & ns \\
\hline & Principal & Local & Ns & + & + & ns & + \\
\hline & funding & Foreign Partners & + & + & + & ns & + \\
\hline & & tervention area & Ns & ns & - & ns & - \\
\hline & Expe & rience of the NGO & Ns & ns & - & ns & - \\
\hline & & Number of staff & Ns & ns & $\mathrm{ns}$ & $\mathrm{ns}$ & $\mathrm{ns}$ \\
\hline
\end{tabular}

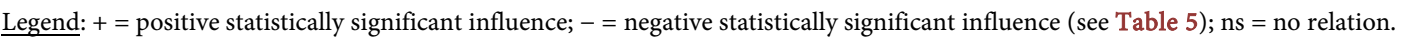

of discharge, care coordination after discharge, and access to pain relief. While Haddad's grouping [37] is more compact (including in the staff dimension all things related to competence, availability, and reception/humane attitude), ours and Wilson's [38] detail these aspects by separately identifying affective and cognitive responses and global satisfaction. Similarly, whereas Haddad et al. [37] emphasized, in their service offer dimension, accessibility to medicines, Wilson et al. [38] preferred to emphasize continuity of care and access to pain management, and our grouping highlights general accessibility, resources, and continuity of care. Indeed, even though continuity of care has been found to be an important dimension in many other contexts [19], accessibility of care and resources and reception/humane attitude can be considered contextual concerns, given the difficulty of accessing care in Africa in general, on one hand, and the poor reputation of the behavior of staff at public health facilities [42], on the other. Finally, the first identified dimension (staff availability and competence) can be considered the very core of caring action (staff competence) and includes many underlying dimensions identified in other contexts, such as the staff s communicative and technical abilities [16] [20] [22] [43]. The fundamental difference between our context and those of Haddad et al. [37] and Wilson et al. [38] is that those authors were interested in measuring the satisfaction of patients receiving essentially curative care, whereas in our study most participants were receiving preventive services (preventive advice and tracking of HIV).

Two of our three individual factors were associated to client satisfaction and 
its dimensions (even though the strength of these associations was very weak, and even imperceptible), the exception being continuity of care. The gender effect can be explained, on one hand, by the fact that feminization of the HIV/AIDS epidemic and gender discrimination in economic power have rendered women more vulnerable [44], making them more sensitive to the efforts of civil society organizations to facilitate their burden. On the other hand, they are always at the forefront in seeking care both for themselves and for their children, which also explains their greater sensitivity to the efforts of NGOs. The age effect is consistent with findings in the literature [31] [32] [33] [34] [36] which suggest that satisfaction increases with age. To improve their performance and client satisfaction, HIV/AIDS NGOs are well advised to pay particular attention to services for men and adolescents, although not to the detriment of services to women and the elderly.

Involvement in evaluation was negatively associated with reception and humane attitude, while the field of intervention and NGO staff numbers had no influence on global satisfaction nor on any of its dimensions. Grytten et al. [28] in Norway found a staff number effect on satisfaction (the larger an NGO, the more services were offered and the more satisfied its clients were regarding accessibility). With respect to principal source of funding, compared with NGOs funded by foreign countries, those mainly funded by foreign partners had clients who were more satisfied globally and in terms of the three dimensions (the exception being continuity of care); the same was true for those with local funding, except that their clients were not more satisfied with staff availability and competence. This may be due to the fact that these foreign partners of Beninese NGOs have relatively different requirements regarding client satisfaction than do the State and its decentralized structures. Clients of more experienced NGOs operating in urban or semi-urban areas were less satisfied globally and with the dimension of accessibility to care and resources than were those of less experienced NGOs operating in rural areas. This observation ran counter to our assumption that more experienced NGOs operating in urban areas, being more open to the outside world, would attract more external funding and would thereby be more effective and have more satisfied clients than those in rural areas. However, this was consistent with our observation in the field, which was that technical and financial partners of NGOs think that because those in urban area are more visible, they obtain substantial funding from government; thus, those partners prefer to concentrate their efforts and funding on NGOs in rural areas, which they consider needier. As a result, NGOs in rural areas have more resources than do those in urban areas and can better satisfy their clients.

\subsection{Contributions and Implications of the Study}

The primary contribution of this study has been to identify, from a cross-sectional survey of clients receiving both preventive and curative services, reception and humane attitude and accessibility of care and resources as two specific dimensions of satisfaction in our context, and staff availability and 
competence and continuity of care as two more universal dimensions of this satisfaction. Another contribution relates to the effects of organizational factors, which have various influences on global satisfaction and its dimensions, and explain from $12.5 \%$ to $15.6 \%$ of the variance of global satisfaction and its dimensions (except for continuity of care). This report is in contrast to the study by Hekkert et al. [32] in the Netherlands, who found in a multilevel analysis in two populations of patients (inpatients and outpatients) that most of the explained variance was at the individual level, with very low variance at the hospital and departmental levels. Those findings enable planners and decisions makers to make decisions in knowing role that each factor plays in a given context.

\subsection{Limitations of the Study}

However, our study has certain shortcomings that limit the scope of our conclusions. First, some of our client recruitment was conducted on NGO sites, such that low users of HIV/AIDS care and services were under-represented. Second, complete standardization of the procedure for administering the questionnaire was not possible. Each of six regions covered by the survey had its own local language, so interviewers were hired and trained based on their capacity to convey the French questionnaire into the local language of their region. Third, the large amount of incomplete/missing data in PCA didn't facilitate identification of the satisfaction dimensions. Fourth, some biases inherent to satisfaction surveys, such as the preservation of self-interest bias, social desirability and insinuating responses, the theory of cognitive consistency, the selection bias due to pre-service perceptions [45] and sensitivity to the Hawthorne effect were unavoidable. Finally, client satisfaction is related to the degree to which expectations are met, but these expectations may not be related to the healthcare quality [46]. Patients may have difficulty assessing many technical aspects of their care accurately, and so the information coming from patients, while important, does not paint a complete picture of healthcare quality [16]. Thus, for a more complete picture it is useful to combine several approaches to incorporate patients' views into systems for managing not only diseases, but health in general, in order to implement evidence-based practices, improve patients' adherence to treatments, and increase as their satisfaction with care [47].

Finally, this multilevel analysis permits us to note that both individual and organizational factors play together to influence clients' satisfaction. A simple logistic regression analysis will be unable to state specific contributions of each level factor.

\section{Conclusion}

This study on client satisfaction in Beninese NGOs enabled us to identify four dimensions of this satisfaction relevant to this context, along with the factors influencing them. It is important for NGOs and their partners to understand these dimensions in order to plan and implement actions to improve performance. 
However, each actor in the healthcare system has a role to play in the improvement process. Professionals need to engage in dialogue with patients and families to share information and, if possible, decision-making. Meanwhile, decision-makers and NGOs' financial and technical partners must also commit to supporting patients as co-producers of healthcare. This will help not only to strengthen the fight against the HIV/AIDS pandemic in particular, but also to improve population health in general.

\section{Acknowledgements}

The authors acknowledge Canadian French-speaking fellowship program (Programme Canadien de Bourse de la Francophonie) for PhD fellowship to principal researcher and for sponsoring field data collection. We thank all NGO leaders and clients in Benin who agreed to participate in this work.

\section{Conflicts of Interest}

The authors declare no conflicts of interest regarding the publication of this paper.

\section{References}

[1] Joint United Nations Program on HIV/AIDS (UNAIDS) (2019) 2019 Global AIDS Epidemic Update. Joint United Nations Program on HIV/AIDS (UNAIDS), Geneva.

[2] Collectif de concertation des Associations et organisations non gouvernementales du Mali (CCA ONG) (2004) 100 millions de personnes pourraient mourir du SIDA d'ici 2025. http://initiatives-mali.info/spip.php?article80

[3] Thelot, F.-L.E. (2009) Le VIH/sida en Afrique du Sud et en Haïti: De l'échec de la gouvernance de l'épidémie aux difficultés d'atteindre les OMD. Cahiers D’études et de Recherches Francophones/ Santé, 19, 121-132. https://doi.org/10.1684/san.2009.0170

[4] Ndiaye, P., El Hadj, O.A., Diedhiou, A., et al. (2005) Évaluation de l'utilisation du préservatif chez les élèves du collège El Mina de Nouakchott, en République islamique de Mauritanie. Cahiers D’études et de Recherches Francophones/Santé, 15, 189-194.

[5] Gibbs, D., Napp, D., Jolly, D., et al. (2002) Increasing Evaluation Capacity within Community-Based HIV Prevention Programs. Evaluation and Program Planning, 25, 261-269. https://doi.org/10.1016/S0149-7189(02)00020-4

[6] Bradley, J., Mayfield, M., Mehta, M., et al. (2002) Participatory Evaluation of Reproductive Health Care Quality in Developing Countries. Social Science \& Medicine, 55, 269-381. https://doi.org/10.1016/S0277-9536(01)00170-8

[7] Hoole, E. and Patterson, T. (2008) Voices from the Field: Evaluation as Part of a Learning Culture. New Directions for Evaluation, 2008, 93-113. https://doi.org/10.1002/ev.270

[8] Fetterman, D. and Wandersman, A. (2005) Empowerment Evaluation: Principles in Practice. The Guilford Press, New York.

[9] Mattessich, P., Mueller, D. and Holm-Hansen, C. (2009) Managing Evaluation for Program Improvement at the Wilder Foundation. New Directions for Evaluation. 
New Directions for Evaluation, 2009, 27-42. https://doi.org/10.1002/ev.283

[10] Crow, R., Gage, H., Hampson, S., et al. (2002) The Measurement of Satisfaction with Healthcare: Implications for Practice from a Systematic Review of the Literature. Health Technology Assessment, 6, 1-244. https://doi.org/10.3310/hta6320

[11] Webster, T.R., Mantopoulos, J., Jackson, E., et al. (2011) A Brief Questionnaire for Assessing Patient Healthcare Experiences in Low-Income Settings. International Journal for Quality in Health Care, 23, 258-268. https://doi.org/10.1093/intqhc/mzr019

[12] Robinson, J., Callister, L. and Lynn, C. (2008) Patient-Centered Care and Adherence: Definitions and Applications to Improve Outcomes. Journal of the American Academy of Nurse Practitioners, 20, 600-607.

[13] Greenslade, J. and Jimmieson, N. (2011) Organizational Factors Impacting on Patient Satisfaction: A Crosssectional Examination of Service Climate and Linkages to Nurses'Effort and Performance. International Journal of Nursing Studies, 48, 1188-1198. https://doi.org/10.1016/j.ijnurstu.2011.04.004

[14] Lin, C.-C. (1996) Patient Satisfaction with Nursing Care as an Outcome Variable: Dilemmas for Nursing Evaluation Researchers. Journal of Professional Nursing, 12, 207-216. https://doi.org/10.1016/S8755-7223(96)80095-0

[15] Sitzia, J. and Wood, N. (1997) Patient Satisfaction: A Review of Issues and Concepts. Social Science \& Medicine, 45, 1829-1843. https://doi.org/10.1016/S0277-9536(97)00128-7

[16] Ashley, S.M. and Strasser, S. (1997) The Patient as a Valuable Source of Outcomes and Quality Information. Nutrition, 13, 701-702. https://doi.org/10.1016/S0899-9007(97)83021-3

[17] Mishra, P.H. and Mishra, T. (2014) Study of Patient Satisfaction at a Super Specialty Tertiary Care Hospital. Indian Journal of Clinical Practice, 25, 624-634.

[18] Thornton, R.D., Nurse, N., Snavely, L., et al. (2017) Influences on Patient Satisfaction in Healthcare Centers: A Semi-Quantitative Study over 5 Years. BMC Health Services Research, 17, Article No. 361. https://doi.org/10.1186/s12913-017-2307-z

[19] Fan, V., Burman, M., McDonell, M., et al. (2005) Continuity of Care and Other Determinants of Patient Satisfaction with Primary Care. Journal of General Intern Medicine, 320, 226-233. https://doi.org/10.1111/j.1525-1497.2005.40135.x

[20] Larson, C., Nelson, N., Gustafson, C., et al. (1996) The Relationship between Meeting Patients' Information Needs and Their Satisfaction with Hospital Care and General Health Status Outcomes. International Journal for Quality in Health Care, 8, 447-456. https://doi.org/10.1093/intqhc/8.5.447

[21] Ahenkan, A. and Aduo-Adjei, K. (2017) Predictors of Patient Satisfaction with Quality of Healthcare in University Hospitals in Ghana. Hospital Practices and Research, 2, 9-14. https://doi.org/10.15171/hpr.2017.03

[22] Peltzer, K. (2009) Patient Experiences and Health System Responsiveness in South Africa. BMC Health Services Research, 9, Article No. 117. https://doi.org/10.1186/1472-6963-9-117

[23] Rajkumari, B. and Nula, P. (2017) Patient's Satisfaction with Care in a Government Health Facility in North East India: A Cross-Sectional study. Journal of Medical Society, 31, 94-98. https://doi.org/10.4103/jms.jms_81_16

[24] Nguyên Thi, T.H., Rasch, V., Chi, B.K.F., et al. (2009) Posttest Counseling and Social Support from Health Staff Caring for HIV-Infected Pregnant Women in Vietnam. Journal of the Association of Nurses in AIDS Care, 20, 193-202. 
https://doi.org/10.1016/j.jana.2009.02.003

[25] Tehrani, A., Feldman, S., Camacho, F., et al. (2011) Patient Satisfaction with Outpatient Medical Care in the United States. Health Outcomes Research in Medicine, 2, 197-202. https://doi.org/10.1016/j.ehrm.2011.09.001

[26] Coovadia, M. (2008) Identification and Evaluation of Patient Satisfaction Determinants in Medical Service Delivery Systems within the South African Private Healthcare Industry. Master of Business Administration, University of Pretoria, Pretoria.

[27] Aiken, L.H., Sloane, D.M., Ball, J., et al. (2018) Patient Satisfaction with Hospital Care and Nurses in England: An Observational Study. BMJ Open, 8, e019189. https://doi.org/10.1136/bmjopen-2017-019189

[28] Grytten, J., Carlsen, F. and Skaua, I. (2009) Services Production and Patient Satisfaction in Primary Care. Health Policy, 89, 312-321. https://doi.org/10.1016/j.healthpol.2008.06.006

[29] Fleishman, J.A., Mor, V. and Piette, J. (1991) AIDS Case Management: The Client's Perspective. Health Services Research, 26, 447-470.

[30] Wouters, E., Heunis, C., Van Rensburg, D. and Meulemans, H. (2008) Patient Satisfaction with Antiretroviral Services at Primary Health-Care Facilities in the Free State, South Africa-A Two-Year Study Using Four Waves of Cross-Sectional Data. BMC Health Services Research, 8, Article No. 210. https://doi.org/10.1186/1472-6963-8-210

[31] Cohen, G. (1996) Age and Health Status in a Patient Satisfaction Survey. Social Science \& Medicine, 42, 1085-1093. https://doi.org/10.1016/0277-9536(95)00315-0

[32] Hekkert, K.D., Cihangir, S., Kleefstra, S.M., et al. (2009) Patient Satisfaction Revisited: A Multilevel Approach. Social Science \& Medicine, 69, 68-75. https://doi.org/10.1016/j.socscimed.2009.04.016

[33] Jenkinson, C., Coulter, A., Bruster, S., et al. (2002) Patients' Experiences and Satisfaction with Health Care: Results of a Questionnaire Study of Specific Aspects of Care. Quality and Safety in HealthCare, 11, 335-339. https://doi.org/10.1136/qhc.11.4.335

[34] Bikker, A.P. and Thompson, A.G. (2006) Predicting and Comparing Patient Satisfaction in Four Different Modes of Health Care across a Nation. Social Science \& Medicine, 63, 1671-1683. https://doi.org/10.1016/j.socscimed.2006.03.022

[35] Nguyen Thi, P.L., Briançon, S., Empereur, F., et al. (2002) Factors Determining Inpatient Satisfaction with Care. Social Science \& Medicine, 54, 493-504. https://doi.org/10.1016/S0277-9536(01)00045-4

[36] Quintana, J.M., González, N., Bilbao, A., et al. (2006) Predictors of Patient Satisfaction with Hospital Health Care. BMC Health Services Research, 6, Article No. 102. https://doi.org/10.1186/1472-6963-6-102

[37] Haddad, S., Fournier, P. and Potvin, L. (1998) Measuring Lay People's Perceptions of the Quality of Primary Health Care Services in Developing Countries. Validation of a 20-Item Scale. International Journal for Quality in Health Care, 10, 93-104. https://doi.org/10.1093/intqhc/10.2.93

[38] Wilson, A., Hewitt, G., Matthews, R., et al. (2006) Development and Testing of a Questionnaire to Measure Patient Satisfaction with Intermediate Care. Quality and Safety in HealthCare, 15, 314-319. https://doi.org/10.1136/qshc.2005.016642

[39] Yergeau, E., Poirier, M., Couture, M., et al. Analyse en composante principale: Rappel théorique. Le site francophone le plus complet sur SPSS17.0.

[40] Raudenbush, W.S. and Bryk, S.A. (2002) Hierarchical Linear Models: Applications 
and Data Analysis Methods. Thousand Oaks, Sage Publications, Charlottesville.

[41] Roberts, J.K. (2004) An Introductory Primer on Multilevel and Hierarchical Linear Modeling. Learning Disabilities. A Contemporary Journal, 2, 30-38.

[42] Berendes, S., Heywood, P., Oliver, S., et al. (2011) Quality of Private and Public Ambulatory Health Care in Low and Middle Income Countries: Systematic Review of Comparative Studies. PLoS Medicine, 8, e1000433. https://doi.org/10.1371/journal.pmed.1000433

[43] Sharma, A., Kasar, P. and Sharma, R. (2014) Patient Satisfaction about Hospital Services: A Study from the Outpatient Department of Tertiary Care Hospital, Jabalpur, Madhya Pradesh, India. National Journal of Community Medicine, 5, 199-203.

[44] Agonnoude, M.T. (2010) La lutte contre les IST/VIH/SIDA: Propositions inspirées de l'expérience des organisations communautaires montréalaises dans ce domaine pour une approche multisectorielle intégrée en milieu rural au Bénin (Cas de la commune de Glazoué, département des Collines). Éditions universitaires européennes, EUE, Sarrebruck.

[45] Agha, S. and Do, M. (2009) The Quality of Family Planning Services and Client Satisfaction in the Public and Private Sectors in Kenya. International Journal for Quality in Health Care, 21, 87-96. https://doi.org/10.1093/intqhc/mzp002

[46] Kane, R. and Maciejewski, M. (1997) The Relationship of Patient Satisfaction with Care and Clinical Outcomes. Medical Care, 35, 714-730.

https://doi.org/10.1097/00005650-199707000-00005

[47] Wensing, M. and Grol, R. (2000) Patients' Views on Healthcare: A Driving Force for Improvement in Disease Management. Disease Manage Health Outcomes, 7, 117-125. https://doi.org/10.2165/00115677-200007030-00001 